\title{
Antioxidant Bio-Complexes from Renewable Arctic Raw Materials
}

\author{
Albina V. Stepanova ${ }^{1}$; Vera V. Anshakova, $\mathrm{PhD}, \mathrm{ScD}^{1}$; \\ Ya. A. Slepokurov'; A.V. Zagorenko ${ }^{3}$; Dmitry M. Uvarov ${ }^{1}$; P. P. Vasilyev ${ }^{1}$ \\ ${ }^{\prime} M$. K. Ammosov North-Eastern Federal University, Yakutsk, Russia \\ ${ }_{2}^{2}$ Saint - Petersburg State Chemical Pharmaceutical Academy, St. Petersburg, Russia \\ ${ }^{3}$ Peoples' Friendship University of Russia, Moscow, Russia
}

\begin{abstract}
We present the results of the investigation of the effect of mechanical activation on the content of low molecular weight antioxidants in powder mixture based on lichen thallus and small amounts of Rhodiola rosea to create nutritional supplements based on them. (Int J Biomed. 2016;6(2):136-137.).
\end{abstract}

Key Words: lichen thallus $\bullet$ Rhodiola rosea $\bullet$ mechanochemical activation $\bullet$ low molecular weight antioxidants

\section{Introduction}

Plants growing in harsh northern conditions attract considerable attention for the production of food additives able to enhance the body's immune system. These plants have to protect themselves from the extreme environmental conditions and therefore produce a range of protective substances including antioxidants.

The purpose of this study was to evaluate the effect of mechanical activation on the content of low molecular weight antioxidants in powder mixture of plant substances to create nutritional supplements based on them.

\section{Materials and Methods}

The object of the study was the physiologically active plant complex with a high level of adaptogenic action, which has been created in "Mechanical Biotechnologies" laboratory of the North-East Federal University. This plant complex is based on plant substances growing in Yakutia: the lichen thallus of Cladonia rangiferina (L.) ("Reindeer moss") and the rhizomes of Rhodiola rosea (Crassulaceae) in weight ratios of 5:1 and 10:1.

The manufacturing of such complexes includes the following operational stages: a) pre-grinding of raw materials

*Corresponding author: Albina V. Stepanova, North-Eastern Federal University, the Republic of Sakha, Yakutsk, Russia.

E-mail: anshakova_v@mail.ru in a high speed mixer KSM-50 (South Korea), b) continuous mixing (for 5 hours) the crushed samples of lichen material and Rhodiola rosea in Lab Powder Mixer ("Junior" Italy), c) the joint mechanical-chemical activation in mechanicalchemical device (ZEM 7-80, Russia) without solvents in a single process step at a speed of $1200-1500 \mathrm{rev} / \mathrm{min}$ for 3.1 $\min .^{[1]}$

Qualitative assessments of the flavonoid content were performed. The total amount of low molecular weight antioxidants (LMWA) was determined using the spectrophotometric method based on the capacity of iron (III) chloride to oxidize LMWA. ${ }^{[2]}$

The studies were performed on eight samples in triplicate. Statistical data analysis was performed.

\section{Results and Discussion}

The multicomponent food additive includes the molecular complexes of lichen $\beta$-polysaccharides and bioactive substances (BAS) from roots and rhizomes of Rhodiola rosea: salidroside and flavonoid aromatic acids formed during mechanochemical activation of the above-mentioned mixture. Investigations with a $5 \%$ alcohol solution of $\mathrm{AlCl}_{3}$ have showed that all samples have acquired yellow-green coloring caused by hydrogen bonds between carbonyl groups and hydroxyl groups, as well as the yellow-green fluorescence of the formed chelate complexes, that indicates the presence of flavonoids in the original samples. In a qualitative reaction with a $1 \%$ basic lead acetate solution, blue amorphous sediment has been formed, that is typical for anthocyanidins. 


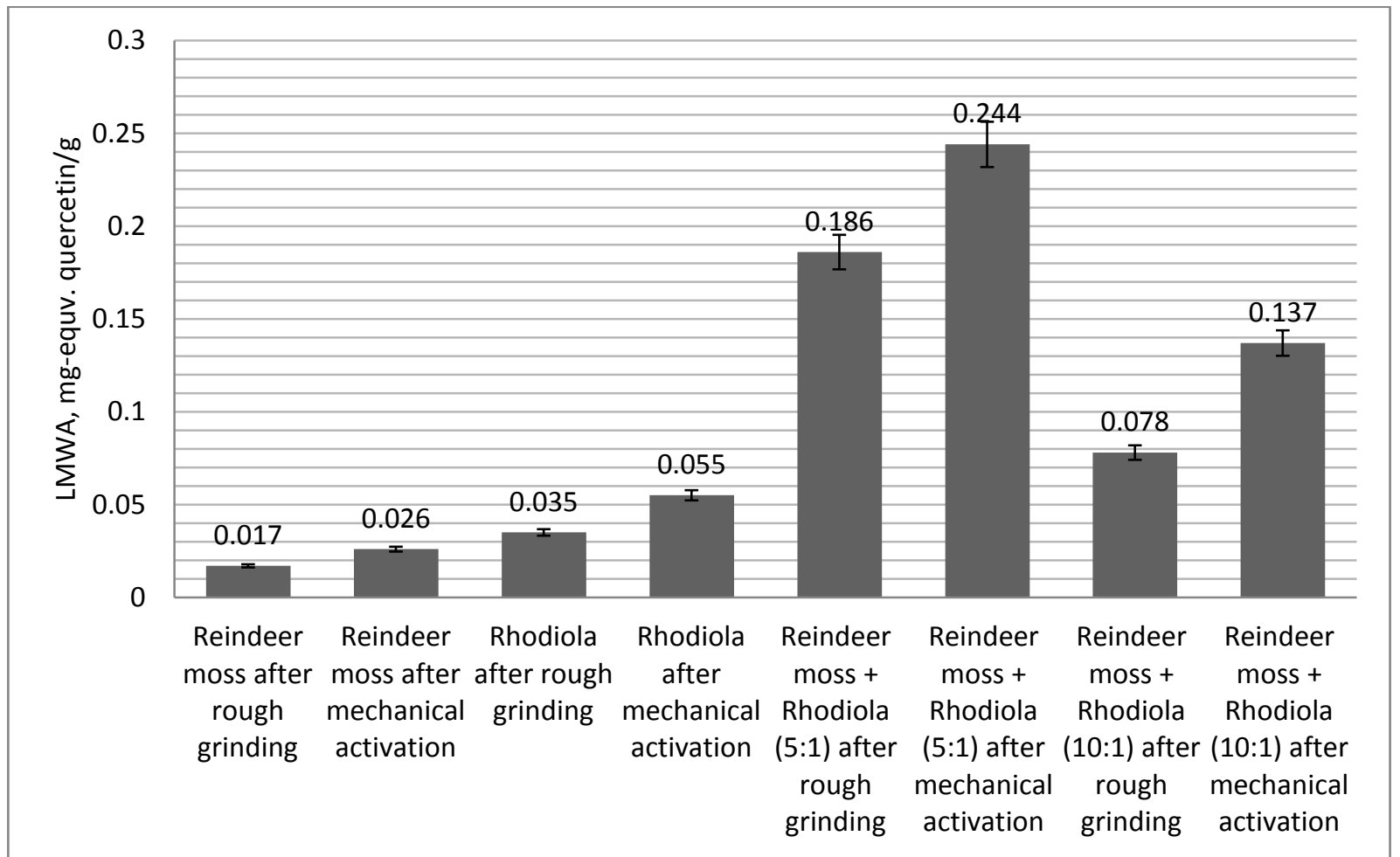

Fig. 1. Total amount of LMWA in the studied samples

The results of spectrophotometric studies indicated that the amount of low molecular weight antioxidants increases during mechanical activation of the raw materials, as well as with an increase in the proportion of the reindeer moss to Rhodiola rosea in the biocomplexes (Fig. 1).

\section{Conclusion}

The use of mechanochemical processing of the raw material destroys the cell walls, where the bulk of the biologically active substances (BAS) is contained, and, as a result, contributes to effective BAS release from the cells.

We have previously developed the new method to improve the quality and preservation of fresh liquid foods and bakery products by adding to their composition of mechanically activated powder mixture of lichen thallus Cladonia P. ${ }^{[3]}$ Mechanically activated samples have greater bioavailability of biologically active substances, which greatly reduces the amount of food additives to $0.1-0.5 \%$ by weight of the finished product. Specification 9110-001-01727661-2012 was developed for making bread "Polarny". Bread "Polar" due to inclusion of bio-supplement "Yagel Detox" stays fresh for a long time, does not grow moldy and acquires special useful properties for human health: optimizes the immune system, increases resistance to viral and bacterial infections, and improves bowel function.
The developed bio-product based on the plant complex of lichen thallus Cladonia rangiferina (L.) and the rhizomes of Rhodiola rosea (Crassulaceae) with using mechanochemical biotechnology is supposed to use as a food additive in very small amounts (less than $0.5 \%$ by weight) to create liquid food products and bakery products having detoxifying properties and abilities to increase the adaptive potential of the human body, as well as the physical and mental capacity. The product may be useful for people having extreme professions, for persons with active lifestyle, people living in adverse environmental and climatic conditions, as well as for athletes in the period of intensive training and patients in the recovery period.

\section{Competing interests}

The authors declare that they have no competing interests.

\section{References}

1. Anshakova VV. The mechanochemical technology for producing of biocomplexes based on lichen material. Int $\mathrm{J}$ Biomed. 2012; 3:232-236. [in Russian].

2. Ermakov AI, Arasimovich VV, Yarosh NP. Methods for Biochemical Investigations of Plants. Revised and Updated 3rd Edition. L.: Agropromizdat; 1987. [in Russian]

3. Anshakova VV, Uvarov DM, Smagulova ASh, Stepanova AV. Mechanochemical biotechnologies: from an idea to production. Proceedings of the 5th Intern. Conf. "Actual Problems of Biochemistry and Bio-nanotechnologies”. Kazan; 2014:18-21. 